\title{
Metal provenance of Late Bronze to Iron Age Hacksilber hoards in southern Levant
}

\author{
DR. LIESEL A GENTELLI ${ }^{1}$, JANNE BLICHERT-TOFT ${ }^{2}$, \\ GILLAN DAVIS $^{3}$, HAIM GITLER ${ }^{4}$ AND FRANCIS \\ ALBARÈDE $^{5}$ \\ ${ }^{1}$ École normale supérieure de Lyon \\ ${ }^{2}$ Ecole Normale Supérieure de Lyon \\ ${ }^{3}$ Department of History and Archaeology, Macquarie University, \\ NSW, Australia \\ ${ }^{4}$ Israel Museum \\ ${ }^{5}$ Ecole Normale Superieure de Lyon \\ Presenting Author: liesel.gentelli@ens-lyon.fr
}

We present new high-precision $\mathrm{Pb}$ isotope data on Hacksilber hoards, interpreted using new, data-driven statistical approaches resulting in samples being grouped in terms of minimizing variance within isotopic clusters, and maximizing variance between clusters. Forty-five pieces of Hacksilber were sampled from five hoards (Megiddo Area H, Eshtemoa, Tel Dor, 'En Gedi, and Tel Miqne-Ekron) and combined with literature data on Hacksilber from the same hoards as well as five further hoards (Beth Shean, Ashkelon, Tell Keisan, Tel 'Akko, and 'Ein Hofez). Sampled silver dates from the Late Bronze Age III (from $1300 \mathrm{BCE}$ ) to the Late Iron Age IIC (until $586 \mathrm{BCE}$ ). We aim to demonstrate the use of new statistical approaches to $\mathrm{Pb}$ isotope analysis of archaeological silver for provenance determination.

In southern Levant, Hacksilber facilitated trade and transactions from the beginning of the second millennium $\mathrm{BCE}$ until the late fourth century BCE. Recent research into Hacksilber provenance mostly concentrated on determining when and to what extent the Phoenicians were engaged in longdistance silver trade prior to their colonisation of the western Mediterranean.

Samples were taken by rolling silver on chromatographic strips of paper impregnated with a solution of $\mathrm{H}_{2} \mathrm{O}_{2}, \mathrm{NH}_{4} \mathrm{OH}$, and $\mathrm{H}_{2} \mathrm{O}$ [1]. Lead was extracted using anion-exchange chromatography, and analysed on a $\mathrm{Nu}$ Plasma $500 \mathrm{MC}-\mathrm{ICP}-$ MS. Data was treated using a new clustering method to identify statistically distinct groups of data, and a convex hull method to identify ore sources consistent with the isotopic signature of each group.

We found that the prevalence of Southern Aegean, Macedonia, Thrace, and Illyria as long-lived major sources of silver show that exchanges between the Levant and the Aegean world never stopped between the Late Bronze Age and the Iron Age III.

Occasional exchanges with Sardinia are confirmed and exchanges with Southern Iberia in the Iron Age are also confirmed. Even if the Aegean world seems to dominate silver supply, exchanges by way of war or trade between the eastern and the western Mediterranean did not disappear from the isotopic record.

[1] Milot, J. et al., 2021. Chem. Geol. 564, 120028. 